\title{
The Active Surveillance of Staphylococcus aureus using Polymerase Chain Reaction-based Identification Method among Hospitalized- patient of Haji Adam Malik General Hospital, Medan, Indonesia
}

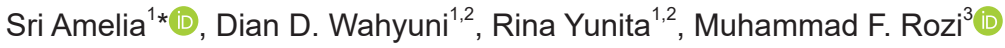 \\ ${ }^{1}$ Department of Microbiology, Faculty of Medicine, Universitas Sumatera Utara, Medan, Indonesia; ${ }^{2}$ Microbiology Installation, \\ Haji Adam Malik General Hospital, Medan, Indonesia; ${ }^{3}$ Department of Parasitology, Faculty of Medicine, Universitas Sumatera \\ Utara, Medan, Indonesia
}

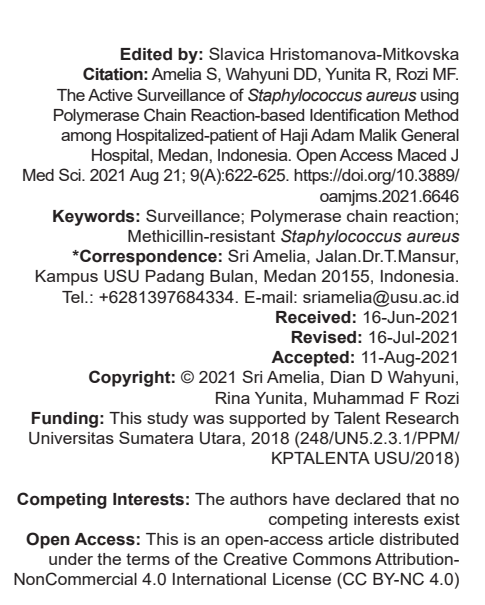

\section{Abstract}

BACKGROUND: Active surveillance of methicillin-resistant Staphylococcus aureus (MRSA) carriers is associated with the lower incidence of bacteremia and lower mortality rates throughout literature; yet, this important step still remains problematic for developing countries, particularly Indonesia.

AIM: The study aimed to demonstrate MRSA colonization rate in Haji Adam Malik Hospital, Medan, Indonesia.

MATERIALS AND METHODS: The study enrolled 200 mucocutaneous isolates obtained from hospitalized patients during a 1-year period of study (2018). VITEK-2 system in addition to standard bacterial identification, such as gram staining, latex agglutination test, and hemolysis pattern, was performed to select $S$. aureus colonies in two different laboratories, Microbiology laboratory of Haji Adam Malik General Hospital and Multidisciplinary Laboratory, Faculty of Medicine, Universitas Sumatera Utara, for polymerase chain reaction (PCR) examination.

RESULTS: Based on the VITEK-2 system preliminary identification, there were $80 \mathrm{~S}$. aureus colonies which then underwent PCR examination. Through standard PCR assay, there were 32 bacterial isolates contained the mecA gene and it can be determined MRSA colonization rate of the hospital was $16 \%$ with consistent results of standard bacterial identification.

CONCLUSIONS: Active surveillance of MRSA carriers is mandatory and urged it as a regular program in a hospital setting to decrease MRSA transmission rate.

\section{Introduction}

Staphylococcus aureus is used to be known susceptible to all types of antibiotics that led Alexander flamming discovered the newly aged era of antibiotic utilization for severe infections [1]. More than a decade later, new cases emerged dramatically and demonstrated several changes of antibiotics susceptibility and resistance to methicillin; the term was introduced to determine one particular strain of $S$. aureus as methicillin-resistant $S$. aureus (MRSA) that carry genes to undermine antibiotic effectivity via transformation of the drug binding sites [2], [3]. MRSA has appeared as the devastating form of bacteria that could provoke irresistible infection as well as cannot be treated by regular antibiotics. The nature of infection was also issued several catastrophic in epidemiologic and economic aspects, such as high mortality rate and prolonged hospitalization. MRSA also become world pandemic that accounts for $5-60 \%$ of mortality rate, highly depends on population and type of infection [4], [5].
$S$. aureus is well-documented throughout literature as human commensal as well as pathogen. Its primary habitat in anterior nares made the bacteria vulnerable to transmit without any difficulty to other people. There are approximately $20 \%$ of persistent $S$. aureus colonizer and $30 \%$ of intermittent colonizer [6]. In addition, there are few notable regions could be colonized such as the gastrointestinal tract, axillary, and groin [7]. In fact, the infection caused by $S$. aureus commonly occur as a result of host immunity breaching, such as through wound, aspiration, insertion of foreign tools (catheters or prosthetic valves), or surgery and the causative organism is identical to the colonizing strain of $S$. aureus around the human body of similar patients. The problems emerged if $S$. aureus colonies would conceive the mecA gene in colonized-region that healthy carriers could transmit and produce MRSA infection [8].

Penicillin Binding Protein 2 (PBP2) is recognized as the binding sites of beta-lactam antibiotics to halt the formation of bacterial peptidoglycan through cross-linking reaction producing osmotic rupture. Nevertheless, MRSA can hinder the bactericidal effect of 
beta-lactam antibiotics by encoding mecA that produces low-affinity PBP (PBP2A) to beta-lactam antibiotics [9]. The transmission of mecA is also obvious; since as the part of mobile genetic element called staphylococcal cassette chromosome mec, mecA could transmit intra- or interspecies horizontally [10]. The identification method of MRSA consists of standard and advanced laboratory testing; standard identification involves a wide variety of bacterial examinations including gram staining, latex agglutination test, sensitivity test while advanced laboratory tests such as polymerase chain reaction (PCR)-based examination or genetic sequencing [11]. The study aimed to demonstrate the MRSA colonization rate in one tertiary referral hospital of Haji Adam Malik General Hospital, Medan, Indonesia among hospitalized patients.

\section{Materials and Methods}

\section{Sample collection}

A total of 200 clinical isolates were obtained from the active surveillance of hospitalized patients in Haji Adam Malik General Hospital for MRSA detection during 12-months periods of study. The samples were swabbed from mucocutaneous at multiple locations including nose and throat with various degrees of illnesses. First, the swab was embedded with a tube containing brain heart infusion broth medium to undergo sample inoculation onto blood agar and mannitol salt agar (MSA) (Oxoid, United Kingdom) for 24-h incubation at $37^{\circ} \mathrm{C}$. The appearance of any suspected colonies of $S$. aureus would proceed colonies to the standard and advanced bacterial identification using gram staining, agglutination test (Pastorex Staph-Plus, Bio-Rad, France), and VITEK-2 system (bioMerieux, France) which was then interpreted by a microbiologist.

\section{PCR method}

Bacterial isolates were handled in a biosafety cabinet class II with a vacuum compression for the DNA extraction and identification using the standard PCR assay with specific primers of mecA 533 base pair (bp) fragment (forward, 5'-AAAATCGATGGTAAAGGTTGGC-3' and reverse, 5'-AGTTCTGGAGTACCGGATTTGC-3') [12]. Colonies for DNA extraction were obtained from blood agar of positive $S$. aureus colonies based on the results of gram staining, agglutination test, and VITEK-2 system and it was extracted using DNA extraction kit in accordance to manufacturer's instruction. The final result of DNA extraction and PCR assay containing PCR buffer, $\mathrm{MgCl}$, dNTP, Taq Polymerase, Master Mix (Ampliqon, Denmark) as well as sterilized water were placed in one microtube. DNA amplification was performed using Mastercycler gradient (Eppendorf, Germany) based on standard thermal cycling protocol consisting of $95^{\circ} \mathrm{C}$ for $3 \mathrm{~min}$, DNA denaturation at $92^{\circ} \mathrm{C}$ for $1 \mathrm{~min}$ (33 cycles), followed by $56^{\circ} \mathrm{C}$ for 1 min during annealing process, and lastly at $72^{\circ} \mathrm{C}$ for 3 min (extension). The visualization of PCR products was then conducted using $2 \%$ agarose gels by electrophoresis and stained by ethidium bromide.

\section{Results}

There are 200 mucocutaneous clinical isolates, which then underwent further examination using VITEK-2 identification system. Final results proved that there were only 80 isolates which were positive for $S$. aureus colonies; Therefore, a total of 80 bacterial isolates was re-inoculated into blood agar and MSA and incubated at $37^{\circ} \mathrm{C}$ for $24 \mathrm{~h}$. There was consistent evidence between the remaining identification methods that 80 isolates demonstrated the existence of $S$. aureus colonies, based on gram staining and Pastorex results. Furthermore, PCR assay was conducted parallel to the examination of standard identification method. The expression of the mecA gene was detected among 32 bacterial isolates $(80 \%)$ and automatically categorized as MRSA [Figure 1]. The rest 48 isolates demonstrated no mecA expression in the PCR examination. Based on PCR assay, the MRSA colonization rate among hospitalized patients in Haji Adam Malik General Hospital, Medan, Indonesia was 16\%.

\section{Discussion}

In the study, MRSA colonizer was observed in $16 \%$ of hospitalized patients regardless of bacterial culture results and symptomatology of patients. MRSA carriers have been associated with the prevalence of MRSA bacteremia in hospitalized patients worldwide; nevertheless, the findings of colonizer individual reluctantly conduct in the officials of a health setting unless several precautious indicators emerge, such as any symptoms of systemic infection [13]. In developing countries, it is not an obligatory examination to regularly identified health-staff or patients as MRSA carriers whereas the health implication of MRSA carriers is notable throughout scientific reports. In Western Nepal, active surveillance of health workers demonstrated $15.7 \%$ of MRSA carriers among 204 people with the highest found among nurses $(7.8 \%)$, while $13 \%$ found among community in the United States. All carriers demonstrated higher vulnerability to suffering from skin and soft tissue infection after 3.6 years of observation in further investigation [14], [15]. 


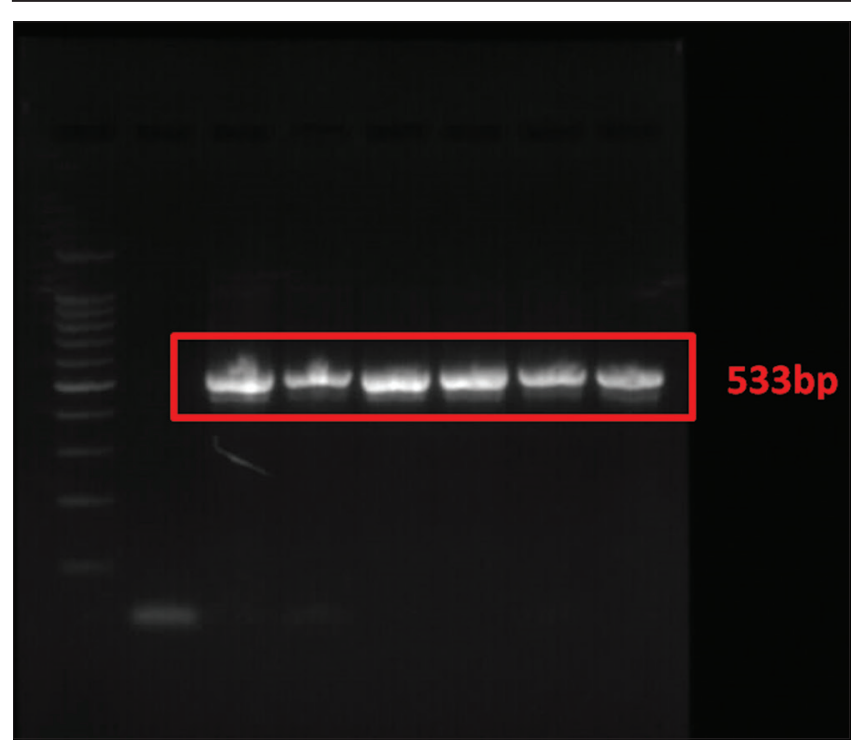

Figure 1: mecA expression through standard polymerase chain reaction assay

Several developed country has owned the eradication strategy to prevent MRSA transmission since the incidence of MRSA among $S$. aureus bacteremia, reaching $30 \%$ in hospital setting although the infection-control has been established [16]. Therefore, active surveillance appears as the answer to promote the eradication of MRSA carriers in the hospital and community settings. However, the program has been implemented in several regions with no definite evaluation system assessing the efficacy of the strategy, mainly during outbreaks [17]. Furthermore, each MRSA carrier has a distinct pattern of colonizing behavior; for instance, a persistent carrier with the highest burden of MRSA colonizer in a different location is the most transmissible individuals compared to the other types of carrier. Meanwhile, intermittent and transient carriers usually obtain negative results when the colonies suddenly disappear. The site of surveillance has also been questioned since not all carriers demonstrate MRSA colonies in anterior nares but this location shows the most frequent colonizer than other sites in the human body [16].

The great importance of MRSA active surveillance has reduced the number of healthassociated infection caused by MRSA per se. In a hospital, a huge burden of MRSA reservoir findings was associated with the decreased number of bacteremia per month after the administration of eradication treatment to positive MRSA colonizer. The study report also suggested MRSA contact isolation enhanced preventive strategy against MRSA transmission [18]. In Japan, active surveillance culture has expanded the coverage for MRSA carrier detection and reduced MRSA transmission rate, the study also demonstrated the superiority of active screening culture policy by involving infection-control practitioners [19]. Meanwhile, a study investigation observed MRSA incidence has decreased significantly through multivariate regression analysis after performing culture surveillance of intensive care patients [20]. Nelson et al. also suggested surveillance strategy must be accompanied by MRSA decolonization to maximize economic effect through reducing mortality rate and infections [21]

\section{Conclusions}

MRSA colonization among hospitalized patients poses a threat to the outcome of therapy, particularly forming irresistible infection that finally produces higher morbidity and mortality rate. Active surveillance appears as one of preventive strategy to reduce the number of MRSA bacteremia and infection as well as decolonization strategy of MRSA carriers.

\section{Ethical clearance}

The study has been approve by the ethical medical research committee, Faculty of Medicine, Universitas Sumatera Utara, Medan, Indonesia.

\section{References}

1. Chambers HF, DeLeo FR. Waves of resistance: Staphylococcus aureus in the antibiotic era. Nat Rev Microbiol. 2009;7(9):629-41. https://doi.org/10.1038/nrmicro2200

PMid:19680247

2. Foster TJ. Antibiotic resistance in Staphylococcus aureus. Current status and future prospects. FEMS Microbiol Rev. 2017;41(3):430-49. https://doi.org/10.1093/femsre/fux007 PMid:28419231

3. Datta R, Huang SS. Risk of infection and death due to methicillinresistant Staphylococcus aureus in long-term carriers. Clin Infect Dis. 2008;47(2):176-81. https://doi.org/10.1086/589241 PMid:18532892

4. Ayau P, Bardossy AC, Sanchez G, Ortiz R, Moreno D, Hartman $P$, et al. Risk factors for 30-day mortality in patients with methicillin-resistant Staphylococcus aureus bloodstream infections. Int J Infect Dis. 2017;61:3-6. https://doi.org/10.1016/j. ijid.2017.05.010 PMid:28533166

5. Siddiqui $\mathrm{AH}$, Koirala J. Methicillin Resistant Staphylococcus aureus (MRSA). Treasure Island, FL: StatPearls Publishing; 2018.

6. Gordon RJ, Lowy FD. Pathogenesis of methicillinresistant Staphylococcus aureus infection. Clin Infect Dis. 2008;46(Suppl 5):S350-9. https://doi.org/10.1086/533591 PMid:18462090

7. Green BN, Johnson CD, Egan JT, Rosenthal M, Griffith EA, Evans MW. Methicillin-resistant Staphylococcus aureus: an overview for manual therapists. J Chiropr Med. 2012;11(1):64-76. https:// doi.org/10.1016/j.jcm.2011.12.001 


\section{PMid:22942844}

8. Kwok KO, Read JM, Tang A, Chen H, Riley S, Kam KM A systematic review of transmission dynamic studies of methicillin-resistant Staphylococcus aureus in non-hospital residential facilities. BMC Infect Dis. 2018;18(1):188. https://doi. org/10.1186/s12879-018-3060-6

PMid:29669512

9. Turner NA, Sharma-Kuinkel BK, Maskarinec SA, Eichenberger EM, Shah PP, Carugati M, et al. Methicillinresistant Staphylococcus aureus: An overview of basic and clinical research. Nat Rev Microbiol. 2019;17(4):203-18. https:// doi.org/10.1038/s41579-018-0147-4

PMid:30737488

10. Garoy EY, Gebreab YB, Achila OO, Tekeste DG, Kesete R, Ghirmay R, et al. Methicillin-resistant Staphylococcus aureus (MRSA): Prevalence and antimicrobial sensitivity pattern among patients a multicenter study in Asmara, Eritrea. Can J Infect Dis Med Microbiol. 2019;2019:8321834. https://doi. org/10.1155/2019/8321834

PMid:30881532

11. Gajdács M. The continuing threat of methicillin-resistant Staphylococcus aureus. Antibiotics. 2019;8(2):52. https://doi. org/10.3390/antibiotics8020052

PMid:31052511

12. Pournajaf A, Ardebili A, Goudarzi L, Khodabandeh M, Narimani T, Abbaszadeh H. PCR-based identification of methicillin-resistant Staphylococcus aureus strains and their antibiotic resistance profiles. Asian Pac J Trop Biomed. 2014;4(Suppl 1):S293-7. https://doi.org/10.12980/apjtb.4.2014c423

PMid:25183100

13. Moyo SJ, Nkinda L, Majigo M, Mmbaga E, Mbembati N, Aboud S, et al. Prevalence of methicillin-resistant Staphylococcus aureus carriage on admission among patients attending regional hospitals in Dar es Salaam, Tanzania. BMC Res Notes. 2017;10(1):417. https://doi.org/10.1186/s13104-017-2668-8 PMid:28830510

14. Khanal R, Sah P, Lamichhane P, Lamsal A, Upadhaya S, Pahwa VK. Nasal carriage of methicillin resistant Staphylococcus aureus among health care workers at a tertiary care hospital in Western Nepal. Antimicrob Resist Infect Control. 2015;4(1):39. https://doi.org/10.1186/s13756-015-0082-3
15. Stevens AM, Hennessy T, Baggett HC, Bruden D, Parks D, Klejka J. Methicillin-resistant Staphylococcus aureus carriage and risk factors for skin infections, Southwestern Alaska, USA. Emerg Infect Dis. 2010;16(5):797-803. https://doi.org/10.3201/ eid1605.091851

\section{PMid:20409369}

16. Bradley SF. Eradication or decolonization of methicillin-resistant Staphylococcus aureus carriage: What are we doing and why are we doing it? Clin Infect Dis. 2007;44(2):186-9. https://doi. org/10.1086/510395

PMid: 17173214

17. Mollema FP, Severin JA, Nouwen JL, Ott A, Verbrugh HA, Vos MC. Successful treatment for carriage of methicillinresistant Staphylococcus aureus and importance of follow-up. Antimicrob Agents Chemother. 2010;54(9):4020-5. https://doi. org/10.1128/aac.01240-09 PMid:20547792

18. Shitrit $P$, Gottesman BS, Katzir M, Kilman A, Ben-Nissan $Y$, Chowers M. Active surveillance for methicillin-resistant Staphylococcus aureus (MRSA) decreases the incidence of MRSA bacteremia. Infect Control Hosp Epidemiol. 2006;27(10):1004-8. https://doi.org/10.1086/507914 PMid:17006805

19. Ohkushi D, Uehara $Y$, Iwamoto A, Shimizu K, Hori S, Hiramatsu $\mathrm{K}$, et al. An effective active surveillance method for controlling nosocomial MRSA transmission in a Japanese hospital. J Infect Chemother. 2013;19(5):871-5. https://doi. org/10.1007/s10156-013-0584-y

\section{PMid:23558667}

20. Holzmann-Pazgal G, Monney C, Davis K, Wanger A, Strobel N, Zhong F. Active surveillance culturing impacts methicillinresistant Staphylococcus aureus acquisition in a pediatric intensive care unit. Pediatr Crit Care Med. 2011;12(4):e171-5. https://doi.org/10.1097/pcc.0b013e3181f39222 PMid:20838355

21. Nelson RE, Samore MH, Smith KJ, Harbarth $S$, Rubin MA, CDC Prevention Epicenters Program. Cost-effectiveness of adding decolonization to a surveillance strategy of screening and isolation for methicillin-resistant Staphylococcus aureus carriers. Clin Microbiol Infect. 2010;16(12):1740-6. https://doi. org/10.1111/j.1469-0691.2010.03324.x

PMid:20673265 